\title{
Complications and Disasters After Minimally Invasive Tissue Augmentation with Different Types of Fillers: A Retrospective Analysis
}

\author{
Alperen S. Bingoel ${ }^{1}\left(\mathbb{D} \cdot\right.$ Khaled Dastagir $^{1} \cdot$ Lavinia Neubert $^{2} \cdot$ Doha Obed $^{1} \cdot$ \\ Thurid R. Hofmann ${ }^{1}$ - Nicco Krezdorn ${ }^{1} \cdot$ Sören Könneker ${ }^{1}$ - Peter M. Vogt ${ }^{1}$ • \\ Tobias R. Mett ${ }^{1,3}$
}

Received: 10 August 2021 / Accepted: 20 November 2021/Published online: 22 December 2021

(C) The Author(s) 2021

\begin{abstract}
Background The interest in youthful appearance and rejuvenating procedures is unbroken in our society. Besides surgical procedures, permanent fillers are utilized. The incorrect and unprofessional use of these substances, autoinjections in particular, have devastating results for patients and are challenging for the plastic surgeon. The aim of this retrospective study was to delineate the differences between permanent and non-permanent filler complications and appropriate treatment options.

Methods We conducted a retrospective study and researched the hospital information system in the time period from 2001 to 2020. Patients with unprofessional use of permanent fillers, auto-injections and injections of unformulated substances were determined. Age, gender, localization, complications, length of hospital stay, comorbidities, histopathological workups and surgical salvage procedures were noted. Descriptive statistics were calculated.

Results Seventeen patients were identified from 2001 till 2020. In four cases, auto-injections by the patients were the cause, whereas in the other patients the injections were performed by medical staff. Ages range from 18 to 57
\end{abstract}

Alperen S. Bingoel

Bingoel.Alperen@mh-hannover.de

1 Department of Plastic, Aesthetic, Hand and Reconstructive Surgery, Burn Centre, Hannover Medical School, CarlNeuberg-Str. 1, 30625 Hannover, Germany

2 Institute of Pathology, Hannover Medical School, CarlNeuberg-Str. 1, 30625 Hannover, Germany

3 Department of Plastic, Aesthetic, and Reconstructive Surgery, Evangelical Hospital Göttingen-Weende, An der Lutter 24, 37075 Göttingen, Germany years. Fourteen patients were female and three were male. The injected substances could be recognized as synthol, silicone, vaseline, fat tissue, hyaluronic acid as well as nonmedical substances. Surgical procedures were necessary in eleven cases. One patient died because of the underlying diseases.

Conclusion Our results indicate different sequels of filler materials injected in an unprofessional way, possible complications, conservative and surgical techniques to resolve these rare complications. We suggest a staged therapy adjusted to the clinical symptoms. Milder symptoms can be handled conservatively, whereas severe infections, skin breakdowns or persistent granuloma are justifying indications for surgical treatment.

Level of Evidence $V$ This journal requires that authors assign a level of evidence to each article. For a full description of these Evidence-Based Medicine ratings, please refer to the Table of Contents or the online Instructions to Authors www.springer.com/00266.

Keywords Aesthetic surgery · Injectable fillers · Filler complications · Permanent fillers · Self-injection .

Silicone $\cdot$ Vaseline

\section{Introduction}

The demand for youthful appearance, a muscular body composition and appealing sexual characteristics is unbroken in modern society. Besides surgical procedures, different types of soft tissue fillers are favored by the patients and also the practitioners. They promise direct effects and fast recovery times. Fillers, whether permanent or not, have been on the rise in the last years according to 
the statistics of the International Society for Aesthetic Plastic Surgery (ISAPS) [1].

A common and frequently used substance is hyaluronic acid. Generally, it is proven by different research articles to be a safe and biocompatible filler material [2, 3]. Moreover, other materials are injected as well, e.g., paraffin, silicone, petroleum-jelly-based products, synthol and other fatty agents for skin care, which are freely available in retail. The incorrect and unprofessional use of resorbable and non-resorbable substances, particularly auto-injections by laypeople, have devastating results for patients e.g., tissue breakdown, necrosis and severe inflammation [4]. Auto-injections with exogenous non-medical substances increase these risks dramatically.

While swelling or bruising of injected regions with hyaluronic acid can be handled conservatively with cooling, steroids and antibiotics, wounds from permanent filler materials need more attention. These tissue reactions are maintained by an inflammatory process in response to nonauthorized materials. Recurrences are often seen because of the remaining particles in the tissue. Common methods of choice in the acute phase are excision and debridement of the inflamed tissue and the substances. Control of the inflammatory process should be the main priority. Reconstruction is often planned as multiple-stage procedures when primary or secondary closure is not possible.

The aim of this retrospective study was to delineate the differences between permanent and non-permanent filler complications, treatment options as well as salvage strategies in severe cases of filler complications. A detailed analysis of histopathological features and the used materials was included.

\section{Patients and Methods}

We conducted a retrospective study and researched the hospital information system (SAP, Walldorf, Germany) in the time period from 2001 to 2020 at the Department of Plastic, Aesthetic, Hand and Reconstructive Surgery. Inclusion criteria were the use of different types of filler materials as a cause for secondary intervention in our department.

The data of all patients that received professional and unprofessional use of filler materials, auto-injections and injections of unformulated, non-authorized substances regardless of the anatomical region were collected and included in this study.

The epidemiologic data comprised age as well as gender. Furthermore, the medical records of the patients were reviewed for affected anatomical localization, surgical procedures, complications, histopathological workups, type of injection, formula of the injected material, length of hospital stay and outcome.

Collection and processing of the data were carried out with Microsoft Excel (Microsoft Inc., Redmond, WA). Statistical analysis was performed using Prism 9.0 (GraphPad, La Jolla, CA). Descriptive statistics (mean and standard deviation) were used for the presentation of the provided data.

The present study was approved by the ethics committee of our institution with the approval number 8982_BO_K_2020 and was in line with the ethical standards of the Declaration of Helsinki and its later amendments and comparable ethical standards.

\section{Results}

From 2001 to 2020,17 patients were identified with the use of different types of filler materials. Table 1 presents the complete medical records of all patients included in this study. The mean age distribution was calculated with 40.9 \pm 12.5 years (range $18-57$ ).

In terms of gender, the distribution showed $82.35 \%(n=$ 14) female and $17.65 \%(n=3)$ male patients. The anatomical localizations are shown in Table 2. The lips $(n=7)$ were the most common site for injection of filler materials followed by the periorbital region $(n=3)$.

Surgical therapy was necessary in 11 of $17(65.70 \%)$ patients. One of these patients rejected surgical therapy.

In six patients, the treatment was successful with conservative methods including orally administered antibiotics. These six patients had been injected with hyaluronic acid.

In the surgically treated ten cases, the regimen consisted of radical excision or incision, debridement and primary closure or secondary wound healing. In seven patients, one single surgical procedure was sufficient. One patient had continuous problems because of recurrent granulomas. In one patient, open wound therapy was necessary due to ongoing inflammation.

No recurrent complications were evident in ten patients after the initial treatment in our department. Six patients suffered from recurrent granulomas. In four cases, a second radical excision with primary closure was successful. One patient is still in therapy with surgical procedures performed once a year, because of spread siliconoma. One patient died because of a depleted immune system without any sign of wound healing and malnourished status suffering from acquired immune deficiency syndrome (AIDS) in the final stage.

In four cases, the injections were performed by the patients themselves. In the other 11 patients, the injections 


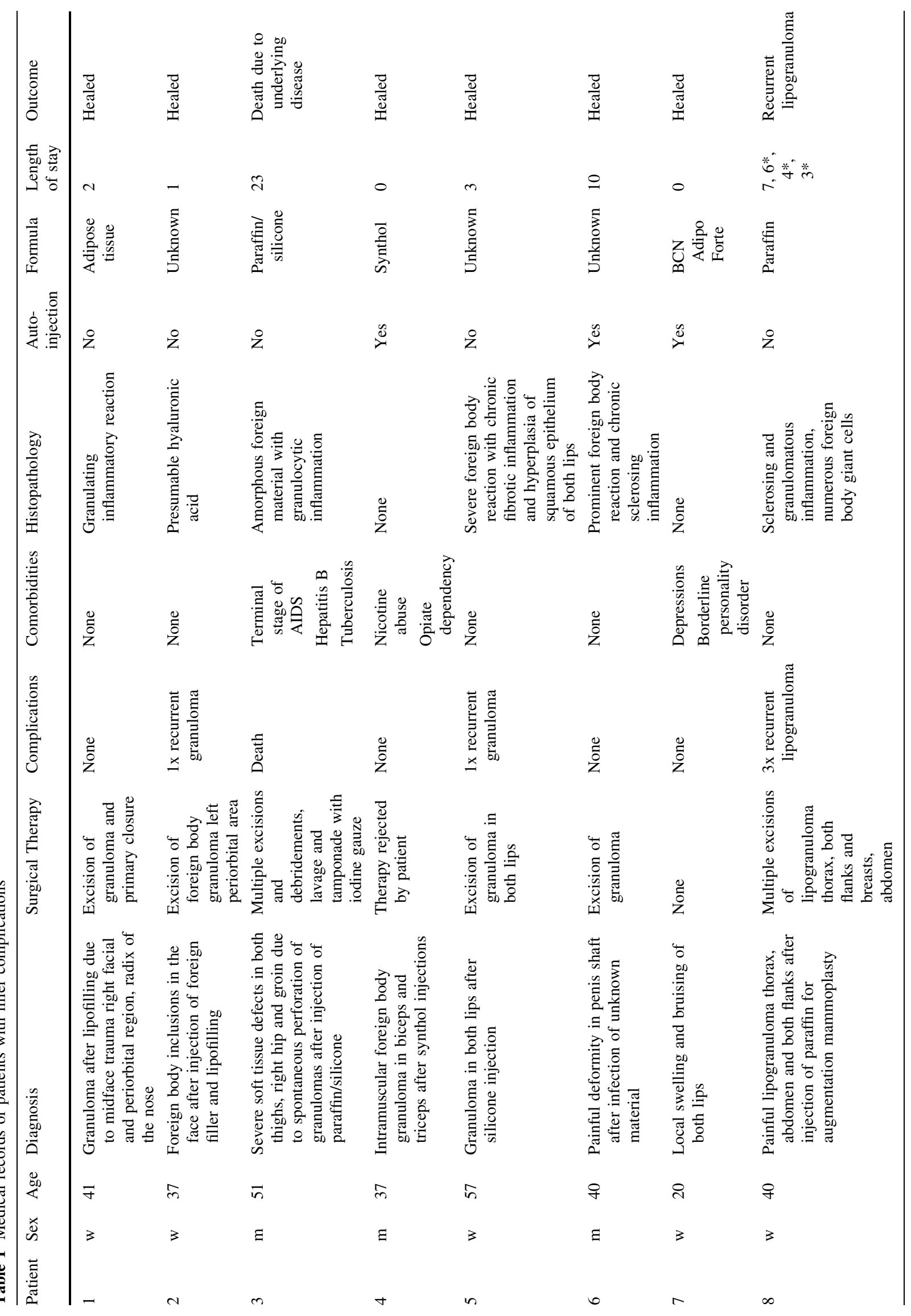




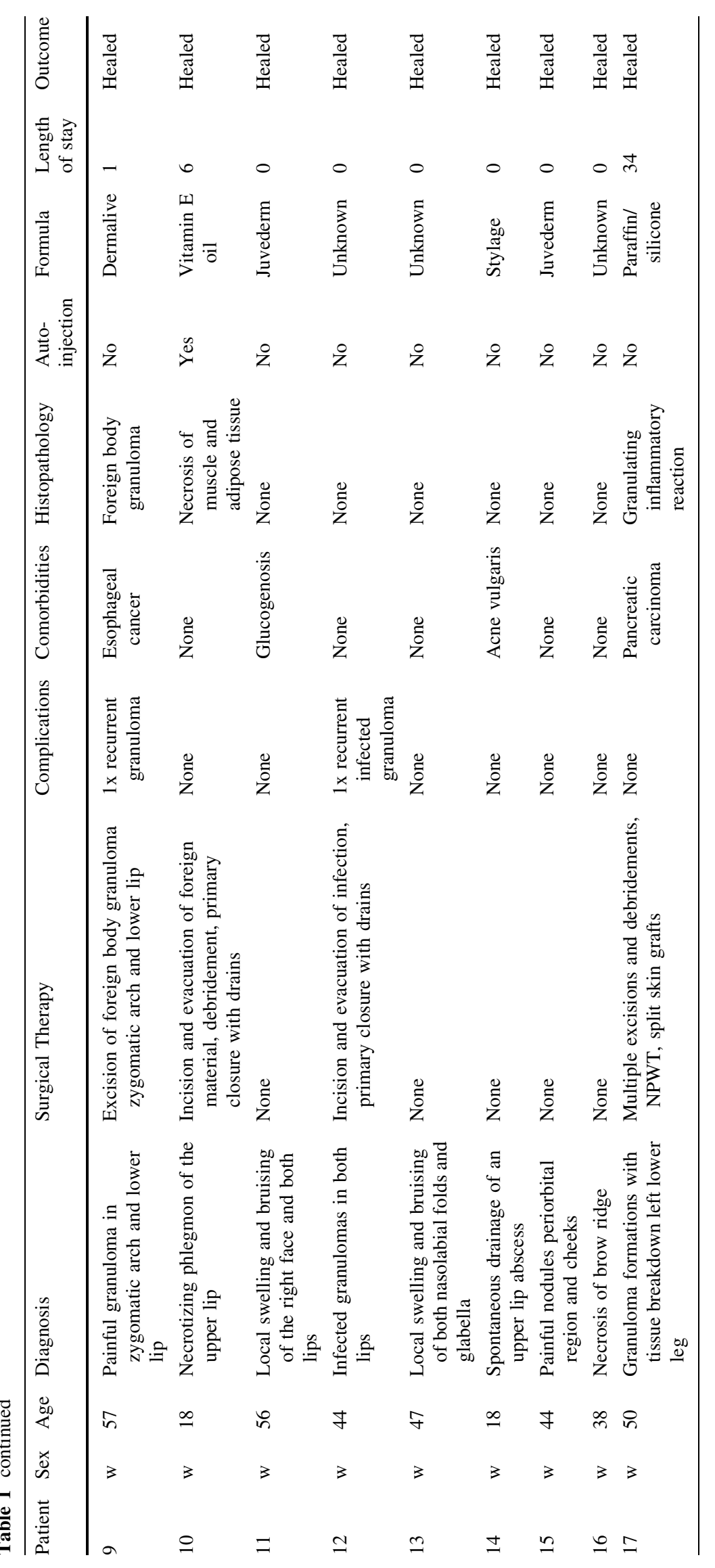


Table 2 Overview of areas injected by fillers

\begin{tabular}{lll}
\hline Face & Periorbital region & $n=3$ \\
& Temporal region & $n=1$ \\
& Lips & $n=7$ \\
& Nasolabial fold & $n=1$ \\
& Glabella/brow ridge & $n=2$ \\
& Cheeks & $n=1$ \\
Trunk & Breasts & $n=1$ \\
Upper extremity & Upper arm & $n=1$ \\
Lower extremity & Thighs, hips, & $n=2$ \\
& lumbar areas & \\
Sexual organs & Penis & $n=1$ \\
\hline
\end{tabular}

were performed by medical professionals, and in one patient by an alternative medicine practitioner.

Histopathological workups were performed in nine cases with various findings that showed inflammation, foreign body inclusions and granulomas (Fig. 1). The histopathologic workup in two patients pointed out the injection of hyaluronic acid as well.

The injected substances could be identified subsequently as hyaluronic acid from different trademarks, synthol, paraffin, silicone, petroleum jelly, adipose tissue and vitamin E oil. Three cases are presented in depth below.

Nine patients were treated in-house; the other eight patients received ambulatory treatment. The mean length of the nine inpatients accounted for $10 \pm 11.4$ days (range 1-34) without readmissions.

Table 2 shows the different sites of injection.

\section{Case report 1}

The clinical course of an 18-year-old woman who presented in our emergency room with a necrotizing phlegmon of the upper lip was noteworthy. She auto-injected a nonmedical formula of vitamin $\mathrm{E}$ oil into her upper lip for augmentation purposes. The upper lip was severely inflamed with tissue breakdown and purulent exudate (Fig. 2a). We decided to perform multiple incisions with debridement of inflamed tissue and the foreign material. The wound was partially closed with small tubes (Fig. 2b, c). Additionally, intravenous antibiotics (amoxicillin and clavulanic acid) were administered for 5 days, the tube was removed on the 2nd postoperative day, and secondary healing was intended. Figure 2d, e outlines the pleasant outcome after almost 6 weeks postoperatively.
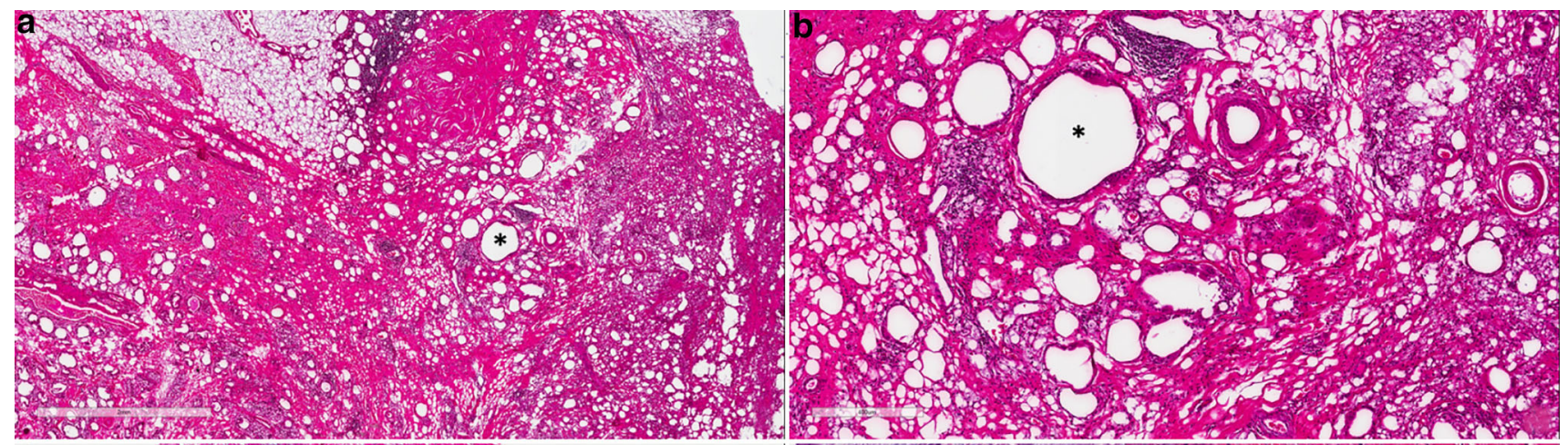

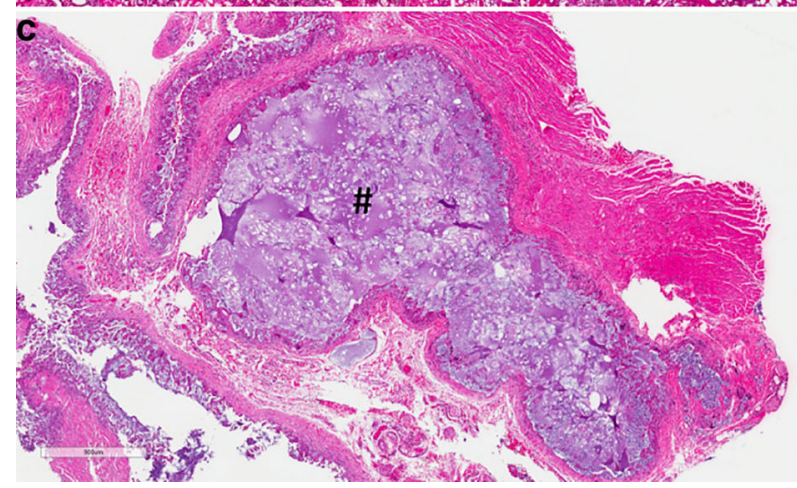

Fig. 1 Histopathology of paraffin injection (a and $\mathbf{b}$ ) and hyaluronic acid injection (c and d) Adipose tissue, interspersed with alternating cellular fibrosis areas with small fibrotically demarcated oil cysts $(*)$ with accompanying calcifications, lymphohistiocytic infiltrates and sometimes grouped multinucleated giant cells of foreign body type

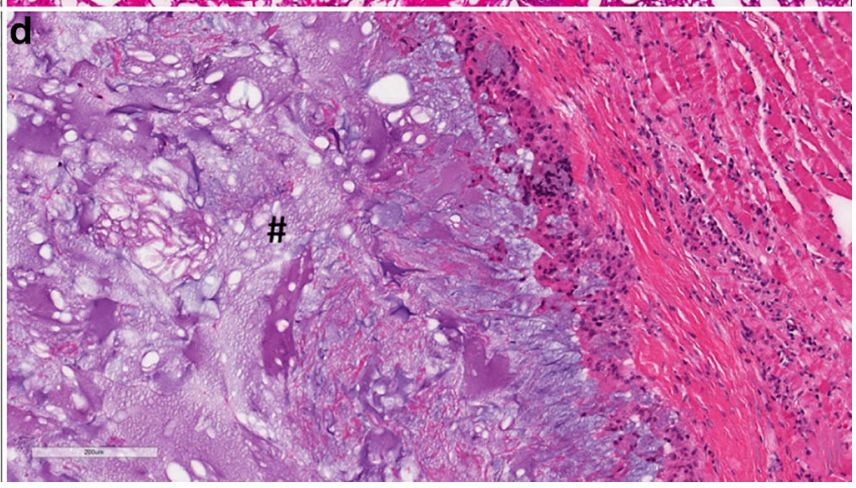

(a and b). Soft tissue with abundant, non-anisotropy foreign material (\#) and numerous surrounding multinucleated giant cells and histiocytes, partially encapsulated (c and d). Scale bars a $2 \mathrm{~mm}$, b $400 \mu \mathrm{m}$, c $900 \mu \mathrm{m}$ and d $200 \mu \mathrm{m}$ 

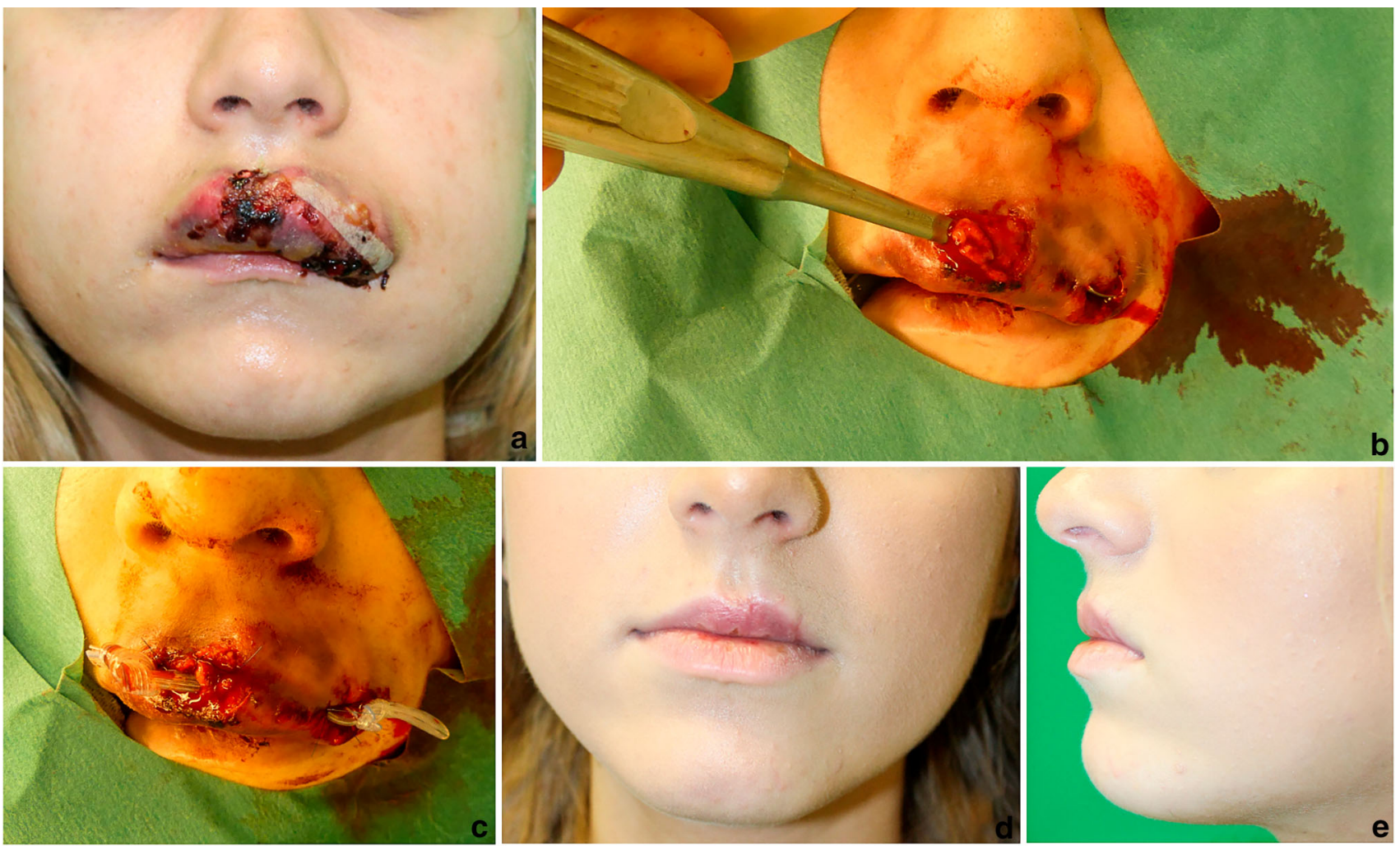

Fig. 2 Clinical course from the initial presentation till full recovery: a shows the initial presentation of the patient with beginning inflammation in the upper lip region after injection. b Presents the intraoperative finding. A sharp curette can be inserted almost fully

into the upper lip. c Displays the direct postoperative result with a partial closure and small plastic tubes. $\mathbf{d}$ and $\mathbf{e}$ Show the postoperative results after full restitutio ad integrum with an aesthetically satisfactory result

\section{Case report 2}

with massive tissue breakdown and wounds (Fig. 3a, b). We performed multiple debridements and favored open wound therapy. Because of a compromised immune system

The second patient was a 51-year-old transsexual woman with paraffin injections almost 20 years ago in the gluteal area. This led to recurrent granuloma formations with spontaneous perforation in both legs, hips and lumbar area based on end-stage AIDS, the patient died due to pulmonary infection.
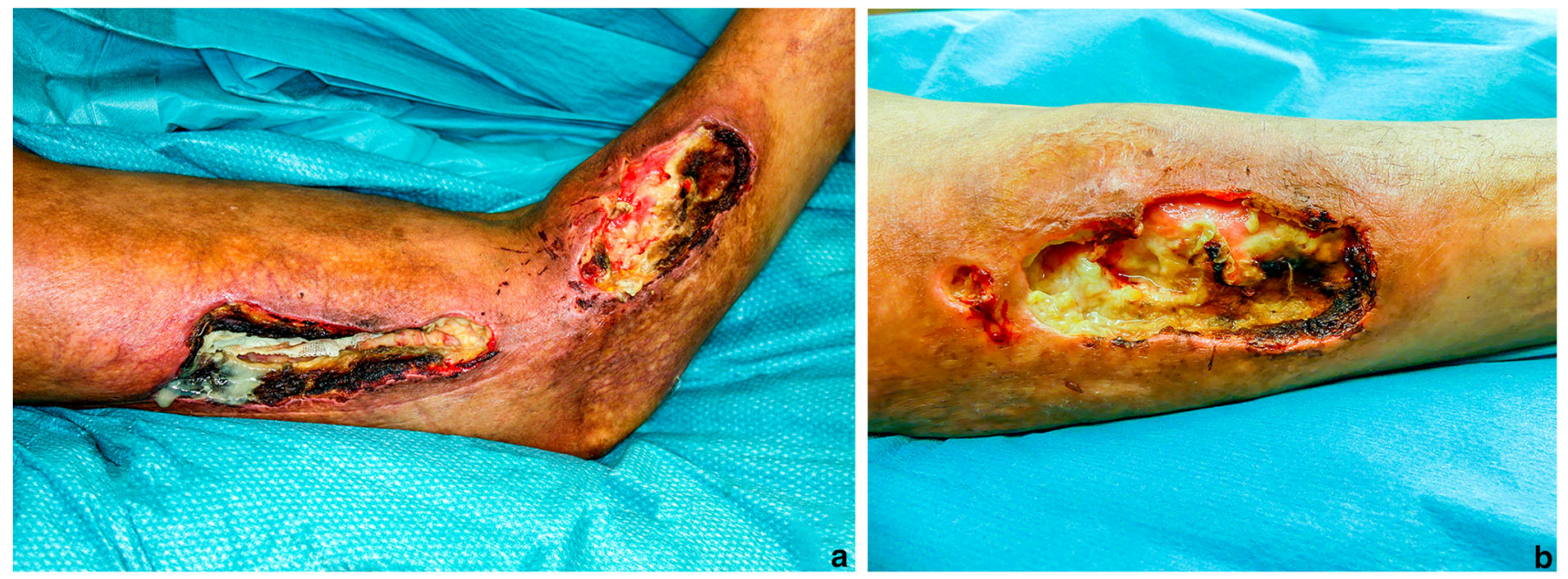

Fig. 3 a and b Present the severe tissue breakdown with necrosis and inflammation of the thigh and lower leg area of the second case before debridement due to paraffin injections in the gluteal area in the second case report 

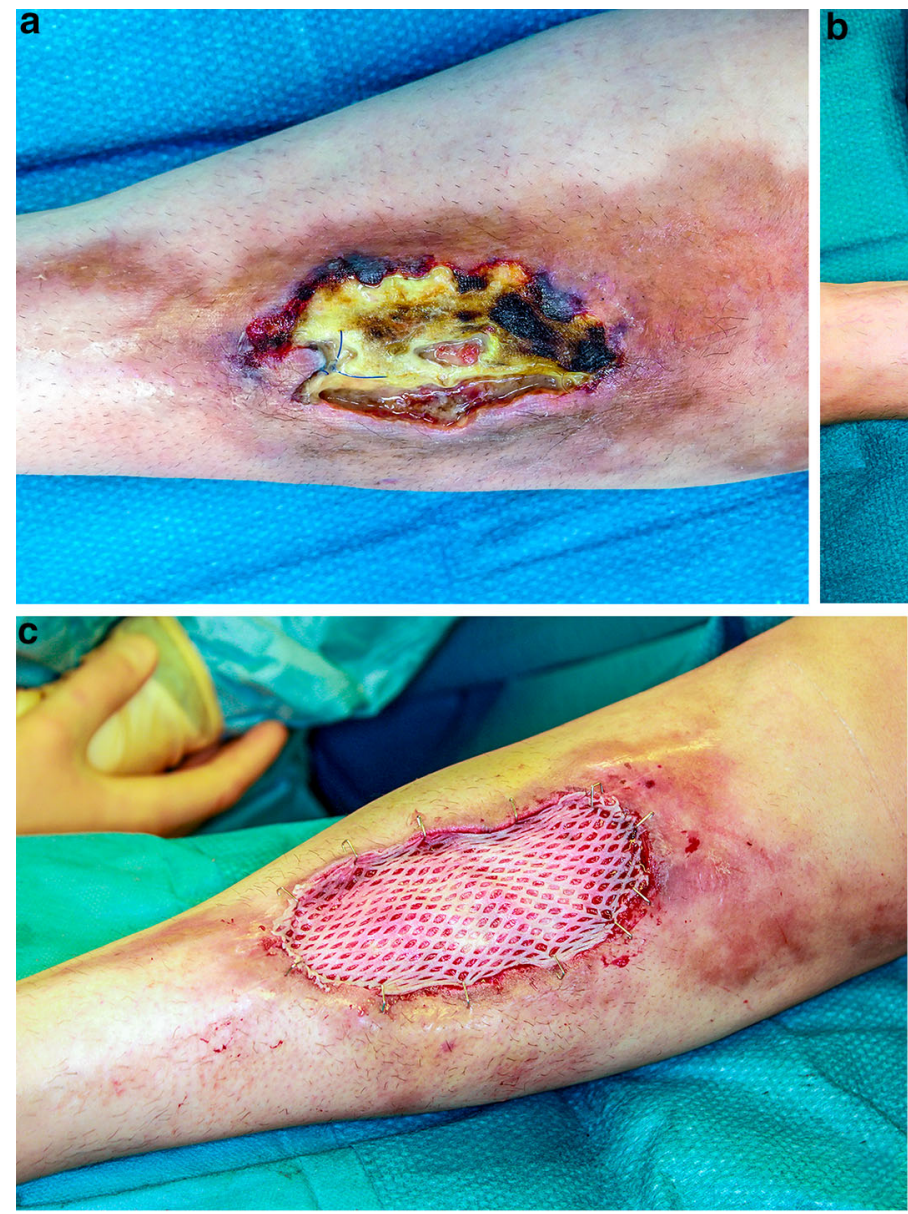
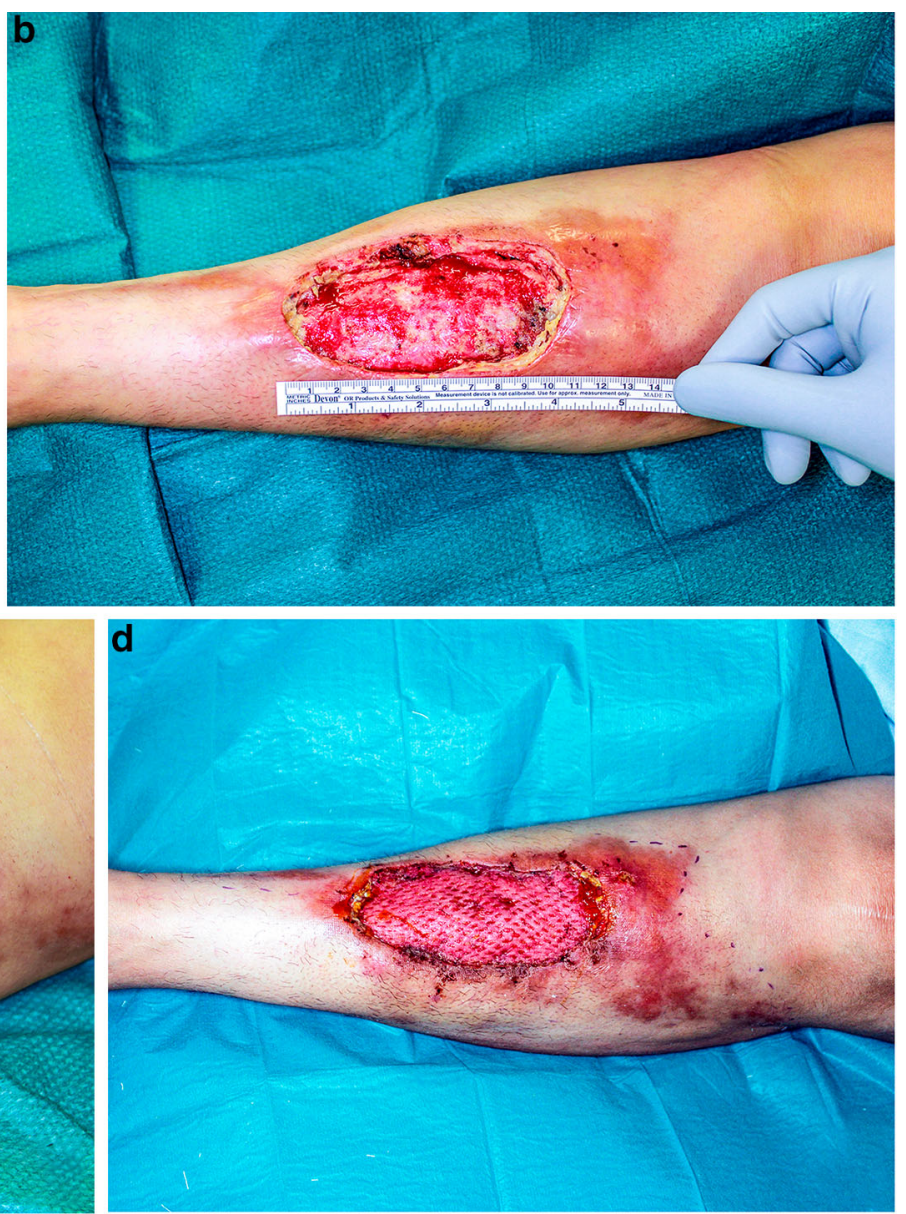

Fig. 4 a Displays the preoperative wound situation of the third case with necrosis and silicone running out of the wound. The injections were performed 20 years ago. After several debridements and

\section{Case report 3}

The third patient was a 50-year-old woman with a chronic wound on the left lower leg. This occurred after silicone injections in the gluteal area about 20 years earlier. There was no history of treatment for the wound. We performed several debridements and negative wound pressure therapy to condition the wound (Fig. 4a, b). Histopathological workups showed granuloma formations based on silicone. The wound was successfully covered with split skin grafts, and the patient could be discharged (Fig. 4c, d).

\section{Discussion}

In this study, we describe a heterogeneous cohort of patients that had received injections of different types of filler materials for aesthetic purposes. The patients were treated for painful and inflamed granuloma formations surgically in 10 of 17 cases. Six patients were treated negative wound pressure therapy (b), split skin grafts were used to cover the wound $(\mathbf{c})$. d Shows the postoperative result

conservatively in a successful manner, and one died because of the preexisting condition of the final stage of AIDS.

The face was the most common region that was subject to injections with two having been auto-injected. In total, we observed four cases with auto-injections.

The treatment of the face with filler materials like hyaluronic acid requires meticulous planning, proper technique and understanding of the anatomical structures. The literature provides plenty of studies in order to reduce the risks and improve safety, particularly using filler materials in facial danger zones [5-7], even though case reports with severe complications were described [8].

In the hands of professionally trained medical staff, hyaluronic acid is a safe and biocompatible filler material [3]. The severity of the complications that were observed in this cohort study like local bruising and swelling is, generally speaking, in line with the data in the literature and can be handled conservatively [9]. Nevertheless, the vascular anatomy of the face is complex and rich of variations. 
This fact also applies to the anatomy of the lips [10]. Even a small amount of filler material can have a big impact on the aesthetic result [11]. Auto-injections of non-medical formula in the face by laypeople without any knowledge can have fatal consequences as we demonstrated in one of our cases. Wolfram et al. reported good functional and aesthetic results of surgical intervention in these cases, if conservative treatments failed [12].

Paraffinomas of the breast are a well-known complication after augmentation mammoplasty with paraffin [13]. This filler material was used widely by unqualified people in the 1950/1960s in China and Europe as well. The injections resulted in grotesque appearances, severe soft tissue damage and sometimes even culminated in mastectomy [14]. Ho et al. described in their study a destruction of the anterior chest wall with ongoing ulcerations and residual multiple paraffinomas in one patient. This description is consistent with the observation in two of our cases. Paraffin provokes tissue inflammation, and despite radical debridement, it seems to remain in the tissue with migration into the adjacent parts of the body like the abdominal wall and even down to the lower extremities. This causes hard nodules, abscesses, fistulas and skin destruction [15]. Di Benedetto et al. delineated a cohort study of 26 patients with paraffinomas and suggested that the wide surgical excision should be the key procedure in the therapy of paraffinomas in the breast and trunk region. In this context, histopathological workups and imaging techniques like MRI or mammography have evidence in cases with ambiguous clinical findings in order to rule out other diseases [16, 17].

The largest case study with a total of 173 patients was published by Park et al. [18]. In total, 121 patients received perilesional surgical excision of the foreign body granulomas with a higher satisfaction rate than the patients who received therapy with steroids or hyaluronidase. Park et al. emphasize the importance of proper patient selection for a successful outcome when favoring a perilesional surgical approach [19].

Auto-injections of foreign materials like paraffin and mineral oils into the penis were described to increase girth of the penis by laypeople in various case reports [20-23]. This can even result in a Fournier's gangrene with catastrophic results [24].

Rosellen et al. recently published treatment strategies for paraffinomas of the penis [25]. For smaller lesions of the penis shaft, they recommend local excision with primary closure which is in line with our treatment strategy in this study. In case of larger lesions with severe inflammation, excision and skin transplantations up to local flaps are feasible options.

Synthol, which we found in one of our patients, is commonly used in the bodybuilding scene to enhance muscular appearance [26-30]. The formula comprises $85 \%$ oil (medium-chain triglycerides), $7.5 \%$ lidocaine and $7.5 \%$ alcohol [27]. The injection is followed by immediate increase in muscle appearance. Complications are lipogranuloma due to the high percentage of oil and progressive tissue destruction [26]. In these cases, radical surgical excision seems to be the only valuable therapy.

Another filler substance that may be found in patients is polymethylmethacrylate (PMMA). PMMA can also lead to granuloma formation. Park et al. demonstrated in 13 patients that both, surgical excision and steroid injections, can be a valuable therapeutic option [31].

Auto-injections of filler materials seem to be an "underreported phenomenon" [4], since there are just some case reports available [32-34]. Even though the unrecorded cases of auto-injections might be much higher, another potential reason might be the costs for secondary treatment which are not covered by any health insurance. Since autoinjections and laymen treatments might be a price-driven decision, the following professional treatment has an economic burden on the patients.

Furthermore, hyaluronic acid as a filler material can be purchased in many countries without prescription. This opens the door for auto-injections or injections by laypeople and underlines the necessity for legal control of these substances.

Fat grafting and transfer into scar regions is a reconstructive strategy that gained attention in the last years due to supporting evidence [35-39]. However, late inflammatory changes of adipose tissue after lipofilling into scarslike in one of our cases-were rarely reported [40, 41]. Sa et al. reported nine patients with lipogranuloma and inflammatory reactions after autologous fat injections (42). Six patients required surgical excisions. Although lipofilling for reconstructive purposes seems to be a safe procedure, surgeons should be aware of complications like inflammatory lipogranuloma.

In summary, a staged therapy with watchful waiting and topical cooling, steroids and antibiotics are applicable in milder symptoms. Severe infections, skin breakdowns or persistent granuloma are justifying indications for surgical treatment. In dependence of the soft tissue quality and wound situation, a partial closure or open wound therapy might be the best choice. Even in secondary healing cases, an aesthetically reasonable result might be achieved or reconstructed by secondary corrections.

Limitations of this study are mainly the retrospective nature of the study design and the small number of cases. This caused a lack of traceability in some of our cases about the used materials and techniques. Nevertheless, this study can help clinicians to overview different types of filler materials, possible complications and conservative and particularly surgical techniques to resolve these rare complications. 


\section{Conclusion}

Aesthetic treatments with permanent and non-permanent filler materials have been on the rise lately. Patients and clinicians should be aware of possible complications like foreign body granuloma beside milder symptoms like bruising and swelling. There seems to be supporting evidence that surgical excision is a safe and effective therapy, especially when non-medical fillers were used with severe complications. Furthermore, we deem it justified to require prescription for filler materials that are currently freely available.

Funding Open Access funding enabled and organized by Projekt DEAL. The authors received no funding or financial support for the research of this article.

\section{Declarations}

Conflict of interest The authors declare that they have no conflict of interest.

Ethical approval All procedures performed in studies involving human participants were in accordance with the ethical standards of the institutional and/or national research committee and with the 1964 Declaration of Helsinki and its later amendments or comparable ethical standards.

Informed consent For this type of retrospective study, informed consent is not required.

Open Access This article is licensed under a Creative Commons Attribution 4.0 International License, which permits use, sharing, adaptation, distribution and reproduction in any medium or format, as long as you give appropriate credit to the original author(s) and the source, provide a link to the Creative Commons licence, and indicate if changes were made. The images or other third party material in this article are included in the article's Creative Commons licence, unless indicated otherwise in a credit line to the material. If material is not included in the article's Creative Commons licence and your intended use is not permitted by statutory regulation or exceeds the permitted use, you will need to obtain permission directly from the copyright holder. To view a copy of this licence, visit http://creativecommons. org/licenses/by/4.0/

\section{References}

1. International Society of Aesthetic Plastic Surgery (2018) ISAPS International Survey on Aesthetic/Cosmetic procedures 2018. Available from: https://www.isaps.org/wp-content/uploads/2019/ 12/ISAPS-Global-Survey-Results-2018-new.pdf

2. Rohrich RJ, Ghavami A, Crosby MA (2007) The role of hyaluronic acid fillers (Restylane) in facial cosmetic surgery: review and technical considerations. Plast Reconstr Surg 120(6 Suppl):41s-54s

3. Stojanovič L, Majdič N (2019) Effectiveness and safety of hyaluronic acid fillers used to enhance overall lip fullness: a systematic review of clinical studies. J Cosmet Dermatol 18(2):436-443
4. Rauso R, Nicoletti GF, Zerbinati N, Lo Giudice G, Fragola R, Tartaro G (2020) Complications following self-administration of hyaluronic acid fillers: literature review. Clin Cosmet Investig Dermatol 13:767-771

5. Scheuer JF 3rd, Sieber DA, Pezeshk RA, Campbell CF, Gassman AA, Rohrich RJ (2017) Anatomy of the facial danger zones: maximizing safety during soft-tissue filler injections. Plast Reconstr Surg 139(1):50e-e58

6. Freytag DL, Frank K, Haidar R, Rudolph C, Muste J, Schenck TL et al (2019) Facial safe zones for soft tissue filler injections: a practical guide. J Drugs Dermatol 18(9):896-902

7. Ferneini EM, Hapelas S, Watras J, Ferneini AM, Weyman D, Fewins J (2017) Surgeon's guide to facial soft tissue filler injections: relevant anatomy and safety considerations. J Oral Maxillofac Surg 75(12):2667.e1-.e5

8. Ozturk CN, Li Y, Tung R, Parker L, Piliang MP, Zins JE (2013) Complications following injection of soft-tissue fillers. Aesthet Surg J 33(6):862-877

9. Winslow CP (2009) The management of dermal filler complications. Facial Plast Surg 25(2):124-128

10. Cotofana S, Alfertshofer M, Schenck TL, Bertucci V, Beleznay $\mathrm{K}$, Ascher B et al (2020) Anatomy of the superior and inferior labial arteries revised: an ultrasound investigation and implication for lip volumization. Aesthet Surg J 40(12):1327-1335

11. Gladstone HB, Cohen JL (2007) Adverse effects when injecting facial fillers. Semin Cutan Med Surg 26(1):34-39

12. Wolfram D, Tzankov A, Piza-Katzer H (2006) Surgery for foreign body reactions due to injectable fillers. Dermatology 213(4):300-304

13. Alagaratnam TT, Ng WF (1996) Paraffinomas of the breast: an oriental curiosity. Aust N Z J Surg 66(3):138-140

14. Ho WS, Chan AC, Law BK (2001) Management of paraffinoma of the breast: 10 years' experience. Br J Plast Surg 54(3):232-234

15. Di Benedetto G, Pierangeli M, Scalise A, Bertani A (2002) Paraffin oil injection in the body: an obsolete and destructive procedure. Ann Plast Surg 49(4):391-396

16. Erguvan-Dogan B, Yang WT (2006) Direct injection of paraffin into the breast: mammographic, sonographic, and MRI features of early complications. AJR Am J Roentgenol 186(3):888-894

17. Wang J, Shih TT, Li YW, Chang KJ, Huang HY (2002) Magnetic resonance imaging characteristics of paraffinomas and siliconomas after mammoplasty. J Formos Med Assoc 101(2):117-123

18. Park TH, Seo SW, Kim JK, Chang CH (2012) Clinical outcome in a series of 173 cases of foreign body granuloma: improved outcomes with a novel surgical technique. J Plast Reconstr Aesthet Surg 65(1):29-34

19. Park TH, Seo SW, Kim JK, Chang CH (2011) The efficacy of perilesional surgical approach for foreign body granuloma. Plast Reconstr Surg 127(6):121e-e123

20. Ahmed U, Freeman A, Kirkham A, Ralph DJ, Minhas S, Muneer A (2017) Self injection of foreign materials into the penis. Ann R Coll Surg Engl 99(2):e78-e82

21. Santucci RA, Zehring RD, McClure D (2000) Petroleum jelly lipogranuloma of the penis treated with excision and native skin coverage. Urology 56(2):331

22. Dellis AE, Nastos K, Mastorakos D, Dellaportas D, Papatsoris A, Arkoumanis PT (2017) Minimal surgical management of penile paraffinoma after subcutaneous penile paraffin injection. Arab J Urol 15(4):387-390

23. De Siati M, Selvaggio O, Di Fino G, Liuzzi G, Massenio P, Sanguedolce F et al (2013) An unusual delayed complication of paraffin self-injection for penile girth augmentation. BMC Urol 13:66

24. Amin A, Blazevski A (2019) A curious case of Fournier's gangrene. Urol Case Rep 27:101001 
25. Rosellen J, Pflüger M, Bach A, Steffens J, Kranz J (2020) Penile paraffinoma-treatment strategies. Urologe A. 59(11):1371-1376

26. Ghandourah S, Hofer MJ, Kießling A, El-Zayat B, Schofer MD (2012) Painful muscle fibrosis following synthol injections in a bodybuilder: a case report. J Med Case Reports 6(1):248

27. Pupka A, Sikora J, Mauricz J, Cios D, Płonek T (2009) The usage of synthol in the body building. Polim Med 39(1):63-65

28. Maatouk I, Moutran R, Maalouf E (2012) Complication of intramuscular injections of "Synthol" oil in a bodybuilder. Ann Dermatol Venereol 139(5):392-394

29. Ikander P, Nielsen AM, Sørensen JA (2015) Injection of synthol in a bodybuilder can cause chronic wounds and ulceration. Ugeskr Laeger 177(20)

30. Sisti A, Huayllani MT, Restrepo DJ, Boczar D, Manrique OJ, Broer PN et al (2020) Oil injection for cosmetic enhancement of the upper extremities: a case report and review of literature. Acta Biomed 91(3):e2020082

31. Park TH, Seo SW, Kim JK, Chang CH (2012) Clinical experience with polymethylmethacrylate microsphere filler complications. Aesthetic Plast Surg 36(2):421-426

32. Allepot K, Mojallal A, Gerenton B (2020) Self-injection: inescapable DIY and real danger? A case study and literature review. Ann Chir Plast Esthet

33. Raoof N, Salvi SM (2015) Self-injection of dermal filler: an underdiagnosed entity? Br J Dermatol 172(3):782-783

34. Ono S, Hyakusoku H (2010) Complications after self-injection of hyaluronic acid and phosphatidylcholine for aesthetic purposes. Aesthet Surg J 30(3):442-445

35. Spiekman M, van Dongen JA, Willemsen JC, Hoppe DL, van der Lei B, Harmsen MC (2017) The power of fat and its adipose- derived stromal cells: emerging concepts for fibrotic scar treatment. J Tissue Eng Regen Med 11(11):3220-3235

36. Pallua N, Baroncini A, Alharbi Z, Stromps JP (2014) Improvement of facial scar appearance and microcirculation by autologous lipofilling. J Plast Reconstr Aesthet Surg 67(8):1033-1037

37. Negenborn VL, Groen JW, Smit JM, Niessen FB, Mullender MG (2016) The use of autologous fat grafting for treatment of scar tissue and scar-related conditions: a systematic review. Plast Reconstr Surg 137(1):31e-43e

38. Uyulmaz S, Sanchez Macedo N, Rezaeian F, Giovanoli P, Lindenblatt N (2018) Nanofat grafting for scar treatment and skin quality improvement. Aesthet Surg J 38(4):421-428

39. Klinger M, Klinger F, Caviggioli F, Maione L, Catania B, Veronesi A et al (2020) Fat grafting for treatment of facial scars. Clin Plast Surg 47(1):131-138

40. Hopkins KL, Lane B, Zatz LM, Mindelzun RE (1995) Scalp lipogranuloma due to dermal lipid injections: CT and MR findings. AJR Am J Roentgenol 165(1):233

41. Park HE, Kim HT, Lee CH, Bae JH (2014) Delayed lipogranuloma of the cheek following autologous fat injection: report of 2 cases. Int J Clin Exp Pathol 7(9):6391-6394

42. Sa H, Woo K, Suh Y, Kim Y (2010) Periorbital lipogranuloma: a previously unknown complication of autologous fat injections for facial augmentation. Br J Ophthalmol 95:1259-1263

Publisher's Note Springer Nature remains neutral with regard to jurisdictional claims in published maps and institutional affiliations. 